\title{
A DESCRIPTION OF MUSCULOSKELETAL INJURIES IN A CANADIAN POLICE SERVICE
}

\author{
LIANA LENTZ ${ }^{1}$, DONALD VOAKLANDER ${ }^{1}$, DOUGLAS P. GROSS ${ }^{2}$, CHRISTINE A. GUPTILL ${ }^{3}$, \\ and AMBIKAIPAKAN SENTHILSELVAN ${ }^{4}$ \\ University of Alberta, Edmonton, Canada \\ ${ }^{1}$ School of Public Health, Injury Prevention Centre \\ ${ }^{2}$ Faculty of Rehabilitation Medicine, Department of Physical Therapy \\ ${ }^{3}$ Faculty of Rehabilitation Medicine, Department of Occupational Therapy \\ ${ }^{4}$ School of Public Health
}

\begin{abstract}
Objectives: Police officers run a risk of injury that is higher than in most other occupations. This study aims to quantify injury prevalence and identify common musculoskeletal injuries (MSIs) among police officers, using injury data from a municipal police service in Alberta, Canada. Material and Methods: This is a descriptive study based on a secondary data analysis of the MSIs reported to the police service over a 41-month period; January 1, 2013 - June 2, 2016. Data from 1325 active police officers were examined, and injury prevalence was reported according to sex, injury diagnosis, the body part injured, and the work area. Results: The prevalence of strains and sprains was very high, at $89.2 \%$. The back and shoulder were most frequently affected. Overall, injury proportions did not differ significantly across work areas. The injury risk was age-related but no significant differences in injuries between sexes were identified. Conclusions: Minor injuries such as strains and sprains occur frequently in the police occupation. Future research should focus on specific risk factors for MSIs in police officers in order to aid prevention. Int J Occup Med Environ Health. 2020;33(1):59-66
\end{abstract}

Key words:

police, occupation, musculoskeletal, prevalence, injury, sprains and strains

\section{INTRODUCTION}

Police officers perform tasks that are vast and varied, ranging from reading to children in an elementary school to chasing down a suspect wanted for a violent crime. Their responsibilities include preventing crime, apprehending those to be taken into custody, and fostering a cooperative relationship with the community. With these responsibilities comes the opportunity to interact with a large number of different people, whether invited or not, which can lead to hostile or dynamic situations that put them at increased risk for injury compared to those in other occupations [1]. This presents a public health problem affecting both civilians and police officers. The individual suffering an injury may experience increased job stress, decreased productivity, limited physical ability, or the development of chronic or comorbid injury. Members of the community are affected by decreased service, increased response time to emergencies, and increased costs of maintaining services.

There is very little research regarding the epidemiology of police officer injury. Research involving first responders

Funding: this study was supported by the Government of Alberta (grant No. RES00029480 entitled "Government of Alberta OHS Futures - Research Funding Program," project manager: Prof. Donald Voaklander).

Received: March 6, 2019. Accepted: September 11, 2019.

Corresponding author: Liana Lentz, University of Alberta, School of Public Health, Injury Prevention Centre, 8308 114 St, Edmonton, AB, T6G 2E1 Canada (e-mail: llentz@ualberta.ca). 
indicates that this occupational group has a 3 times greater risk of being injured at work than all other occupations [2]. Additionally, it has been reported that firefighters have an injury rate 7 times that of the U.S. national average [3], and police officers have a $10 \%$ greater occurrence of injuries compared to firefighters [1]. Much research has been done in regard to police officer occupational health and safety in terms of the impact of shift work [4,5], fatigue [6], catastrophic or fatal injury [7], violence [8] and the use of force technologies (e.g., baton, oleoresin capsaicin spray, conductive energy device) [9-12]. Even though the risk of musculoskeletal injury (MSI) for police officers is high (RR: 11.65, 95\% CI: 11.07-12.25) [2], research regarding MSI is lacking [8,13]. Because MSIs such as sprains, strains, dislocations, and fractures have been somewhat overlooked in the literature, the frequency of police officer injury may be underestimated.

The objectives of this study are to analyze injury data from a municipal police service in Western Canada in order to quantify injury prevalence, and to identify the most common MSIs experienced by police officers.

\section{MATERIAL AND METHODS}

This was a cross-sectional study of active police officers in a municipal police service in Western Canada. The mean number of police officers in this agency in 2013-2016 was 1674/year (312 female, 1362 male) [14]. Medical data were recorded by the Police Service using specialized injury report software in January 1, 2013 - June 2, 2016. Data were extracted from the police service medical database by the data manager, and a subset of this data relating to MSIs was analyzed. An employee of the police service removed names and changed identification numbers prior to providing it to the researchers so that no individual could be identified. Data were obtained with a permission from the Police Service, and according to the Freedom of Information and Protection of Privacy Act. Ethical approval for this study was obtained from the University of Alberta Health Research Ethics Board.
The dataset was comprised of any reported injuries that occurred in January 1, 2013 - June 2, 2016, and included the date of injury, date of birth, body part injured, diagnosis, work area, and sex. Cases of MSIs were identified through diagnostic categories compiled by the Police Service (dislocation, fracture, knee meniscus tear, non-specific pain, and sprain/strain). The body areas injured were classified as upper extremities, lower extremities, torso, or head/neck. The body parts injured were classified as ankle, arm, back, elbow, feet and toes, groin, hands and fingers, hip, knee, leg, multiple body parts, neck, shoulder, spine, and wrist. Any duplicate cases were identified based on the identification number, injury date, and body part injured, and were removed prior to the analysis. Only the first recorded injury for each subject was included in the analysis.

A descriptive analysis was conducted that included the frequencies and proportions of reported injuries. Injuries were classified according to the diagnosis, body region, and body part. Comparisons were made between sex, age, work area, and the length of service. The prevalence rate was calculated by dividing the number of police officers who reported a new MSI during the observation period by the number of active police officers in the sample. Cumulative incidence was calculated over the 41-month observation period. Proportions between groups were statistically compared using the $\chi^{2}$ statistic and odds ratios with $95 \%$ confidence intervals (CIs). Continuous variables were compared using a t-test to obtain the significant differences between the means. Parameter estimators were normally distributed according to the quantile-quantile (Q-Q) plots. A p-value of $\leq 0.05$ was considered significant. The data analysis was conducted using SAS software, Version 9.4 (SAS Institute Inc, Cary, North Carolina).

\section{RESULTS}

In the period of January 1, 2013 - June 2, 2016 there was a yearly average of 1674 active police officers. Demographic and injury data were available for 1325 individuals. The sam- 
Table 1. Distribution of injuries occurring among Canadian police officers in the period of January 1, 2013 - June 2, 2016, stratified by gender and years of service

\begin{tabular}{|c|c|c|c|c|}
\hline \multirow{3}{*}{ Variable } & \multicolumn{4}{|c|}{$\begin{array}{c}\text { Participants } \\
(\mathrm{N}=1325) \\
(\mathrm{M} \pm \mathrm{SD})\end{array}$} \\
\hline & \multicolumn{2}{|c|}{$\begin{array}{c}\text { males } \\
(\mathrm{N}=1062)\end{array}$} & \multicolumn{2}{|c|}{$\begin{array}{c}\text { females } \\
(\mathrm{N}=263)\end{array}$} \\
\hline & $\begin{array}{c}\text { injured } \\
(\mathrm{N}=388)\end{array}$ & $\begin{array}{c}\text { not injured } \\
(\mathrm{N}=674)\end{array}$ & $\begin{array}{c}\text { injured } \\
(\mathrm{N}=93)\end{array}$ & $\begin{array}{c}\text { not injured } \\
(\mathrm{N}=170)\end{array}$ \\
\hline Age [years] & $33.7^{*} \pm 6.3$ & $34.7 \pm 6.6$ & $33.7 \pm 6.4$ & $34.8 \pm 5.9$ \\
\hline Service time [years] & $8.0 \pm 5.0$ & $10.1 \pm 5.9$ & $8.7 \pm 5.5$ & $10.7 \pm 5.2$ \\
\hline
\end{tabular}

$* \mathrm{p}=0.01$.

Table 2. Distribution of injuries occurring among Canadian police officers in the period of January 1, 2013 - June 2, 2016, stratified by sex and work area

\begin{tabular}{|c|c|c|c|c|}
\hline \multirow{3}{*}{ Work area } & \multicolumn{4}{|c|}{$\begin{array}{c}\text { Participants } \\
(\mathrm{N}=293) \\
{[\mathrm{n}(\%)]}\end{array}$} \\
\hline & \multicolumn{2}{|c|}{$\begin{array}{c}\text { males } \\
(\mathrm{N}=238)\end{array}$} & \multicolumn{2}{|c|}{$\begin{array}{c}\text { females } \\
(\mathrm{N}=55)\end{array}$} \\
\hline & $\begin{array}{c}\text { injured } \\
(\mathrm{N}=79)\end{array}$ & $\begin{array}{c}\text { not injured } \\
(\mathrm{N}=159)\end{array}$ & $\begin{array}{c}\text { injured } \\
(\mathrm{N}=24)\end{array}$ & $\begin{array}{c}\text { not injured } \\
(\mathrm{N}=31)\end{array}$ \\
\hline Recruit & $2(2.5)$ & $6(3.8)$ & $2(8.3)$ & 0 \\
\hline Uniform & $51(64.6)$ & $107(67.3)$ & $10(41.7)$ & $19(61.3)$ \\
\hline Administrative & $5(6.3)$ & $6(3.8)$ & $4(16.7)$ & $4(12.9)$ \\
\hline Investigative & $5(6.3)$ & $8(5.0)$ & 0 & $2(6.5)$ \\
\hline Support & $8(10.1)$ & $9(5.7)$ & $5(20.8)$ & $5(16.1)$ \\
\hline Specialized & $3(3.8)$ & $8(5.0)$ & 0 & $1(3.2)$ \\
\hline Plain clothes & $5(6.3)$ & $15(9.4)$ & $3(12.5)$ & 0 \\
\hline
\end{tabular}

ple consisted of 1062 males and 263 females with mean ages of $34.4(\mathrm{SD}=6.1)$ and $34.3(\mathrm{SD}=6.5)$ years, respectively. The mean years of service for females was $10.2(\mathrm{SD}=5.4)$ and $9.5(\mathrm{SD}=5.7$ ) for males. Over 41 months, the cumulative incidence was 106 injuries/1000 personnel/year. Females and males experienced a similar risk of being injured (OR 1.05 [95\% CI: 0.79-1.40]). The female police officers who were injured were not significantly different in terms of the age structure from those who were not injured $(p=0.15)$, but the injured males were significantly younger than those who were not injured $(p=0.01)$. However, for both sexes, the injured officers had significantly less years of policing experience than those who were not injured (Table 1). The mean time to injury, as indicated by years of service, was $8.7(\mathrm{SD}=5.5)$ for females and $8.0(\mathrm{SD}=5.0)$ for males.

Most injuries were diagnosed as sprains/strains (89.2\%) and fractures $(8.3 \%)$ (Table 2). The upper extremities were the most frequently injured body area, accounting 
Table 3. Distribution of injury diagnosis occurring in the period of January 1, 2013 - June 2, 2016 among Canadian police officers, stratified by sex

\begin{tabular}{lccc}
\hline \multirow{2}{*}{\multicolumn{1}{c}{ Diagnosis }} & & $\begin{array}{c}\text { Participants } \\
(\mathrm{N}=481) \\
{[\mathrm{n}(\%)]}\end{array}$ \\
\cline { 2 - 4 } & males & females & total \\
\cline { 2 - 4 } & $(\mathrm{N}=388)$ & $0(0.00)$ & $4(0.8)$ \\
Dislocation & $4(1.0)$ & $4(4.3)$ & $40(8.3)$ \\
Fracture & $36(9.3)$ & $0(0.0)$ & $1(0.2)$ \\
Knee meniscus tear & $1(0.3)$ & $2(2.2)$ & $5(1.0)$ \\
Non-specific pain & $3(0.8)$ & $87(93.5)$ & $431(89.2)$ \\
Sprain/strain & $344(88.7)$ & &
\end{tabular}

Table 4. Distribution of body regions injured by Canadian police officers in the period of January 1, 2013 - June 2, 2016, stratified by sex

\begin{tabular}{lccc}
\hline & & $\begin{array}{c}\text { Participants } \\
(\mathrm{N}=452) \\
{[\mathrm{n}(\%)]}\end{array}$ & total \\
\cline { 2 - 4 } Body region & males & females \\
& $(\mathrm{N}=363)$ & $35(39.3)$ & $168(37.2)$ \\
\hline Upper extremities & $133(36.6)$ & $27(30.3)$ & $161(35.6)$ \\
Lower extremities & $134(36.9)$ & $22(24.7)$ & $91(20.1)$ \\
Torso & $69(19.0)$ & $2(2.3)$ & $28(6.2)$ \\
Head/neck & $26(7.2)$ & $3(3.4)$ & $4(0.9)$ \\
Multiple body regions & $1(0.3)$ & & \\
\hline
\end{tabular}

for $37.2 \%$ of injuries, whereas the lower extremities accounted for $35.6 \%$ of reported injures. The torso was injured $20.1 \%$ of the time, and the least injured body area was the head/neck at $6.2 \%$ (Table 3). More specifically, the back and shoulder were the most frequently injured body parts, accounting for $19.2 \%$ and $13.5 \%$ of all injuries, respectively, followed by the hands and fingers $(12.1 \%)$, ankle (11.3\%) and knee (11.3\%) (Table 4).

Data regarding the work area were limited and concerned only 293 participants. Work areas were classified according to work tasks (recruit training, uniformed, administrative, investigative, support, specialized and plain clothed). The majority of this subsample were uniformed, patrol/beat officers (63.8\%) in that they wore a full uniform and were in contact with the public frequently while responding to calls for service (Table 5). The prevalence of injury by work area ranged $25-48 \%$. When work areas were compared, administrative and support staff (i.e., uniformed officers working in schools, police stations, detention units, or traffic officers) showed the highest prevalence of injuries. However, participants in this work area only made up $6.5 \%$ of this subsample. Overall, injury distribution was not significantly different between work areas $(p=0.62)$; 
Table 5. Distribution of body parts injured by Canadian police officers in the period of January 1, 2013 - June 2, 2016, stratified by sex

\begin{tabular}{|c|c|c|c|}
\hline \multirow[t]{2}{*}{ Body part } & \multicolumn{3}{|c|}{$\begin{array}{c}\text { Participants } \\
(\mathrm{N}=452) \\
{[\mathrm{n}(\%)]}\end{array}$} \\
\hline & $\begin{array}{c}\text { males } \\
(\mathrm{N}=363)\end{array}$ & $\begin{array}{c}\text { females } \\
(\mathrm{N}=89)\end{array}$ & total \\
\hline Abdomen & 0 & $1(1.1)$ & $1(0.2)$ \\
\hline Ankle & $42(11.6)$ & $9(10.2)$ & $51(11.4)$ \\
\hline Arm & $13(3.6)$ & $1(1.1)$ & $14(3.1)$ \\
\hline Back/spine & $67(18.6)$ & $21(23.9)$ & $88(19.6)$ \\
\hline Elbow & $9(2.5)$ & $2(2.3)$ & $11(2.4)$ \\
\hline Feet/toes & $9(2.5)$ & $2(2.3)$ & $11(2.4)$ \\
\hline Groin & $9(2.5)$ & 0 & $9(0.2)$ \\
\hline Hands/fingers & $43(11.9)$ & $12(13.6)$ & $55(12.2)$ \\
\hline Head/face & $3(0.8)$ & $1(1.1)$ & $4(0.9)$ \\
\hline Hip & $4(1.1)$ & $5(5.7)$ & $9(0.2)$ \\
\hline Knee & $44(12.2)$ & $7(8.0)$ & $51(11.4)$ \\
\hline Leg & $26(7.2)$ & $4(4.5)$ & $30(6.7)$ \\
\hline Multiple body parts & $1(0.3)$ & $3(3.4)$ & $4(0.9)$ \\
\hline Neck & $23(6.4)$ & $1(1.1)$ & $24(5.3)$ \\
\hline Ribs & $3(0.8)$ & 0 & $3(0.7)$ \\
\hline Shoulder & $49(13.6)$ & $12(13.6)$ & $61(13.6)$ \\
\hline Wrist & $19(5.3)$ & $8(9.1)$ & $27(6.0)$ \\
\hline
\end{tabular}

however, there was a significantly different distribution of males and females across the work areas $(p=0.02)$. Females figured more prominently in administrative and support positions than males.

\section{DISCUSSION}

During the 41 months investigated, 481 injuries were reported in this group of police officers, indicating an injury incidence rate of 106/1000 person-years. This is greater compared to the findings by Gray and Collie [2] who stated that police officers in Australia had an incidence of MSIs of 46 cases/1000 workers, and to the U.S. Bureau of Labor Statistics reporting that in 2014, among police officers, the rate of nonfatal occupational injuries and ill- nesses requiring time off work was 48.6 cases/1000 full-time workers [15]. Relative to other research, the prevalence of injury in this study is similar to the results previously recorded (85-2500 cases/1000 workers/1 year) [5,8,16-25]. Differences in injury incidence in the existing literature could be due to several methodological factors, including different definitions of injury, the nature of the study, and the source of the data used in the analysis. Varied definitions of injury may explain differences in injury incidence between studies. A broad definition of injury would likely lead to increased injury estimates; however, this does not seem to be the case here. It is also possible that longer observation periods allowed for more injuries, such as repetitive strain injuries, to manifest. 
Sprains were the most dominant injury type accounting for over $89.2 \%$ of all injuries. The back and shoulder were injured most frequently. The results of this study indicate that MSIs, especially sprains, are commonly suffered by police officers which concurs with previous reports. Sprains and strains are commonly prevalent in police officers, accounting for $17-61 \%$ of MSIs [8,23-25]. In the current study, the proportion of strains and sprains was higher, at $88 \%$, outside of the range reported in the literature.

There is some inconsistency in the reported research regarding the most commonly injured area of the body. In general, it appears that police officers injure the upper extremities more frequently than the lower extremities $[20,21]$. The current study is consistent with findings that the back [19,26], shoulder [17], and leg (or lower extremity) $[16,22,23]$ are most frequently injured; however, this study found a lower proportion of injuries to the hand, fingers and wrists $(11.7 \%)$ compared to other police-based research where the hand, wrists and fingers were injured more frequently $(17-21 \%)$ [20,23]. Variations in the use of gloves and the availability of alternative force options (oleoresin capsicum spray, baton, or conducted energy device) may be protective and could account for the differences between studies.

In studies that compare sex, female officers were more likely to file workers' compensation claims [2] or receive compensation [18] but, in general, there was little difference in the injury rates between males and females [16,20], as was reflected in the current study. The increase in workers' compensation claims and the receipt of compensation may be indicative of increased injury severity in female police officers. This information was not available for this study. Further research is thus required.

The difference in mean age between the injured and uninjured males was statistically significant. Though the age of the injured and uninjured females is similar to that of males, the difference in age for the injured and uninjured females is not statistically significant. This is mainly due to their smaller representation in the sample. The literature indicates that police officers of a lower rank [18] or age $[13,20,22]$ are at increased risk for injury, and that police officers $<40$ years old are injured most often $[2,13,20]$. The relationship between age and the injury risk is complex and may be confounded by the rank and occupational task. Younger police officers may be at increased risk for injury, but further investigation is required to ascertain whether it is age that is related to injury or whether younger workers participate in riskier job tasks. For example, patrol officers who respond to calls for service are generally less experienced, younger, and more likely to be involved in dynamic and hostile situations than those who have been promoted to more investigative or administrative positions.

Little research has been done regarding the work area and injury, and the non-significant relationship between these factors found in this study should be interpreted with caution. Accepting the non-significant relationship would require the assumption that the data were missing completely at random. Data regarding the physical task the officers were doing when they became injured was missing for most subjects, so it was not included in the analysis. However, the information that does exist shows a trend that suspect apprehension and physical fitness activities were most frequently associated with injury. Controlling and apprehending suspects [8,24,25], overexertion [20] and training activities have been cited as the most common tasks being performed when a police officer becomes injured. Officer safety skills, tactics, tools, and training are associated with injury occurrence. As an example, the use of a conducted energy device has been shown to decrease the likelihood that officers would need to have direct contact with, or discharge their firearm on, an assaultive or combative person, thereby decreasing injuries to both the officers and the people they deal with [10]. It makes sense then that an area of work which involves an increased opportunity to apprehend suspects may also correlate with an increased risk of injury. 
This study has several limitations. The data used were gathered for administrative purposes and were not intended for research purposes, and the veracity of the data is not known. There are some missing data, but it is not known if this information is missing at random. The injuries recorded are only those that were reported to workplace management and are likely of a more serious nature, thus excluding minor injuries. Existing research indicates that occupational injuries are underreported in many industries. For example, a Canadian survey found that $40 \%$ (95\% CI: 32-48) of workers who suffered a work-related injury had not filed a worker's compensation claim [27].

\section{CONCLUSIONS}

The findings from this study indicate that police officers frequently suffer MSIs, and the greatest proportions of injuries are sprains and strains. Police officers most commonly injure their lower extremity, back, and/or shoulder. Injury prevention efforts should, therefore, focus on these injuries. Future research should investigate individual and organizational risk factors for injuries in order to guide the prevention efforts.

\section{REFERENCES}

1. Suyama J, Rittenberger JC, Patterson PD, Hostler D. Comparison of public safety provider injury rates. Prehospital Emerg Care. 2009;13(4):451-5, https://doi.org/10.1080/10903 120903144908.

2. Gray SE, Collie A. The nature and burden of occupational injury among first responder occupations: A retrospective cohort study in Australian workers. Injury. 2017;48(11):2470-7, https://doi.org/10.1016/J.INJURY.2017.09.019.

3. Szubert Z, Sobala W. Work-related injuries among firefighters: sites and circumstances of their occurrence [cited 2019 Mar 6]. Int J Occup Med Environ Health. 2002;15(1):49-55. Available from http:/www.imp.lodz.pl/home_en/publishing_ office/journals___ijomeh/\&articleId=18113\&l=EN.
4. Violanti J, Fekedulegn D. Shift work and the incidence of injury among police officers. Am J Ind Med. 2012;55(2):21727, https://doi.org/10.1002/ajim.22007.

5. Violanti JM, Fekedulegn D, Andrew ME, Charles LE, Hartley TA, Vila B, et al. Shift work and long-term injury among police officers. Scand J Work Environ Heal. 2013;39(4):3618, https://doi.org/10.5271/sjweh.3342.

6. Fekedulegn D, Burchfiel CM, Ma CC, Andrew ME, Hartley TA, Charles LE, et al. Fatigue and on-duty injury among police officers: The BCOPS study. J Safety Res. 2017;60:4351, https://doi.org/10.1016/j.jsr.2016.11.006.

7. Tiesman HM, Hendricks SA, Bell JL, Amandus HA. Eleven years of occupational mortality in law enforcement: The census of fatal occupational injuries, 1992-2002. Am J Ind Med. 2010;53(9):940-9, https://doi.org/10.1002/ajim.20863.

8. Brandl SG, Stroshine MS. The Physical Hazards of Police Work Revisited. Police Q. 2012;15(3):262-82, https://doi.org/ 10.1177/1098611112447757.

9. Castillo EM, Prabhakar N, Luu B. Factors associated with law enforcement-related use-of-force injury. Am J Emerg Med. 2012;30(4):526-31, https://doi.org/10.1016/j.ajem.2011. 01.017 .

10. Paoline EA, Terrill W, Ingram JR. Police Use of Force and Officer Injuries: Comparing Conducted Energy Devices (CEDs) to Hands- and Weapon-Based Tactics. Police Q. 2012;15(2):115-36, https://doi.org/10.1177/10986111 12442807.

11. Jenkinson E, Neeson C, Bleetman A. The relative risk of police use-of-force options: Evaluating the potential for deployment of electronic weaponry. J Clin Forensic Med. 2006;13(5):229-41, https://doi.org/10.1016/J.JCFM.2005. 11.006.

12. Alpert GP, Dunham RG. Policy and Training Recommendations Related to Police Use of CEDs: Overview of Findings From a Comprehensive National Study. Police Q. 2010;13(3): 235-59, https://doi.org/10.1177/1098611110373993.

13. International Association of Chiefs of Police [Internet]. 2013 [cited 2019 Jan 2]. Reducing Officer Injuries Final Report: 
A Summary of Data Findings and Recommendations from a Multi-Agency Injury Tracking Study. Available from: http:// www.theiacp.org/portals/0/pdfs/IACP_ROI_Final_Report.pdf.

14. Statistcs Canada [Internet]. 2018 [cited 2019 Jan 2]. Police personnel and selected crime statistics, municipal police services. Available from: https://www150.statcan.gc.ca/t1/ tbl1/en/tv.action?pid=3510007701\&pickMembers $\% 5 B 0 \%$ $5 \mathrm{D}=1.531$.

15. US Bureau of Labor Statistics [Internet]. The Bureau; 2016 [cited 2018 Nov 7]. Fact Sheet, Police Officers. Available from: https://www.bls.gov/iif/oshwc/cfoi/police-officers-2014.htm.

16. Reichard AA, Jackson LL. Occupational injuries among emergency responders. Am J Ind Med. 2010;53(1):1-11, https://doi.org/10.1002/ajim.20772.

17. Brandl SG, Stroshine MS. Toward an Understanding of the Physical Hazards of Police Work. Police Q. 2003;6(2):17291, https://doi.org/10.1177/1098611103006002003.

18. Larsen B, Aisbett B, Silk A. The injury profile of an Australian specialist policing unit. Int J Environ Res Public Health. 2016;13(4):370-8, https://doi.org/10.3390/ijerph13040370.

19. Knapik JJ, Grier T, Spiess A, Swedler DI, Hauret KG, Graham B, et al. Injury rates and injury risk factors among federal bureau of investigation new agent trainees. BMC Public Health. 2011;11:920, https://doi.org/10.1186/1471-2458-11-920.

20. Cho T-S, Jeon W-J, Lee J-G, Seok J-M, Cho J-H. Factors Affecting the Musculoskeletal Symptoms of Korean Police Officers. J Phys Ther Sci. 2014;26(6):925-30, https://doi.org/ 10.1589/jpts.26.925.
21. Boyce RW, Hyatt AR, Jones GR. Workers' compensation claims and physical fitness capacity of police officers. J Health Behav Educ Promot. 1992;16(4):22-9.

22. Gyi DE, Porter JM. Musculoskeletal problems and driving in police officers. Occup Med (Lond). 1998;48(3):153-60, https://doi.org/10.1093/occmed/48.3.153.

23. Sullivan CSB, Shimizu KT. Epidemiological studies of workrelated injuries among law enforcement personnel. J Soc Occup Med. 1988;38:33-40, https://doi.org/10.1093/occmed/ 38.1-2.33.

24. Holloway-Beth A, Forst L, Freels S, Brandt-Rauf S, Friedman L. Occupational injury surveillance among law enforcement officers using workers' compensation data, Illinois 1980 to 2008. J Occup Environ Med. 2016;58(6):594-600, https://doi.org/10.1097/JOM.0000000000000708.

25. Nabeel I, Baker BA, McGrail MP, Flottemesch TJ. Correlation between physical activity, fitness, and musculoskeletal injuries in police officers. Minn Med. 2007;90(9):40-3, https://doi.org/10.1097/00005768-199605001-00469.

26. Jahani MR, Motevalian SA, Asgari AR. Musculoskeletal disabilities among police force personnel of the Islamic Republic of Iran. Mil Med. 2002;167(10):850852, https://doi. org/10.1080/02684529908432581.

27. Shannon HS, Lowe GS. How many injured workers do not file claims for workers' compensation benefits? Am J Ind Med. 2002;42(6):467-73, https://doi.org/10.1002/ajim.10142.

This work is available in Open Access model and licensed under a Creative Commons Attribution-NonCommercial 3.0 Poland License - http://creativecommons.org/ licenses/by-nc/3.0/pl/deed.en. 